\title{
Races of Puccinia striiformis f. sp. tritici in the United States in 2011 and 2012 and Comparison with Races in 2010
}

Anmin Wan, Department of Plant Pathology, Washington State University, Pullman 99164-6430; Xianming Chen, United States Department of Agriculture-Agricultural Research Service, Wheat Health, Genetics, and Quality Research Unit; and Department of Plant Pathology, Washington State University, Pullman; and Jonathan Yuen, Department of Forest Mycology and Plant Pathology, Swedish University of Agricultural Sciences, S 75007 Uppsala, Sweden

\begin{abstract}
Wan, A. M., Chen, X. M., and Yuen, J. 2016. Races of Puccinia striiformis f. sp. tritici in the United States in 2011 and 2012 and comparison with races in 2010. Plant Dis. 100:966-975.

Stripe rust, caused by Puccinia striiformis f. sp. tritici, is one of the most important diseases on wheat in the United States. In 2011, severe wheat stripe rust caused extensive application of fungicides in the western United States, and the disease was more widespread and caused more yield loss in the eastern United States in 2012. In this study, we characterized virulences and identified races of $P$. striiformis $\mathrm{f}$. sp. tritici by testing the stripe rust samples collected throughout the United States in 2011 and 2012 on a set of $18 Y r$ single-gene differentials. In 2011, 35 races were identified from 349 viable samples collected from 19 states of the United States and Ontario province of Canada, with PSTv-11 (35.5\%), PSTv-37 (12.6\%), PSTv-14 (11.8\%), PSTv-4 (5.4\%), and PSTV-34 (3.4\%) as the top five predominant races. In 2012, 23 races were identified from 341 viable samples collected from 24 states of the United States and Ontario of Canada, with PSTv-37 (47.5\%), PSTv-11 (11.7\%), PSTv-14 (10.0\%), PSTv-52 (9.4\%), and PSTv-48 $(4.4 \%)$ as the top five predominant races. Nationally, PSTv-37, PSTv-52, and PSTv-34 were most widely distributed, while PSTv-11, PSTv-14, PSTv-4, and PSTv-48 were mostly detected in the western United States.

High frequencies ( $>80 \%$ ) were detected for virulences to $\mathrm{Yr} 6, \mathrm{Yr} 7, \mathrm{Yr}$, $\operatorname{Yr} 9, \operatorname{Yr} 17, \operatorname{Yr} 27, Y r 44$, and $Y r E x p 2$; moderate frequencies (20 to 80\%) for virulences to $Y r 1, Y r 43, Y r T r 1$, and $Y r T y e$; low frequencies $(<10 \%)$ for virulences to $\operatorname{Yr} 10, \operatorname{Yr} 24, \mathrm{Yr} 32$, and $\mathrm{YrSP}$; and virulences to $\operatorname{Yr} 5$ and Yr15 were not detected, indicating that these two genes are still effective against the $P$. striiformis $\mathrm{f}$. sp. tritici population in the United States. Both positive and negative associations were identified between some of the virulences. In total, 55 races identified from 2010 to 2012 in the United States were clustered into two major virulence groups, and dynamics of predominant races and virulence frequencies for the 3 years were presented and discussed. This information is useful for making decisions when screening wheat germplasm for developing stripe-rust-resistant wheat cultivars and managing the disease by growing cultivars with adequate and durable resistance. The severe epidemics and the occurrence of the large number of races in the 3 years indicate that efforts should be made to use diverse resistance genes, especially to combine effective all-stage resistance genes with genes for high-temperature adult-plant resistance.
\end{abstract}

Wheat stripe (yellow) rust, caused by Puccinia striiformis f. sp. tritici Erikss., is a constraint for wheat production worldwide and can cause significant yield losses (Chen 2005; Wellings 2011). In the United States, the disease can cause significant damage in the western United States almost every year and has become increasingly important in the eastern United States (Chen 2005, 2007; Chen et al. 2002, 2010; Line 2002). Developing and growing resistant cultivars is the most effective, economic, easy to use, and environmentally friendly approach for control of the disease (Chen 2005, 2014). However, the P. striiformis f. sp. tritici pathogen is highly variable in virulence because it keeps evolving, producing new races and changing in

\section{Corresponding author: X. M. Chen; E-mail: xianming@wsu.edu}

Mention of trade names or commercial products in this publication is solely for the purpose of providing specific information and does not imply recommendation or endorsement by the United States Department of Agriculture. USDA is an equal opportunity provider and employer.

PPNS number 0696, Department of Plant Pathology, College of Agricultural, Human, and Natural Resource Sciences, Agricultural Research Center, project number WNP00663 (projects 13C-3061-5665 and 13C-3061-4232), Washington State University, Pullman.

*The $\boldsymbol{e}$-Xtra logo stands for "electronic extra" and indicates that one supplementary table is published online.

Accepted for publication 8 December 2015.

http://dx.doi.org/10.1094/PDIS-10-15-1122-RE

This article is in the public domain and not copyrightable. It may be freely reprinted with customary crediting of the source. The American Phytopathological Society, 2016. distribution and frequency of previously existing races. Consequently, these changes in the $P$. striiformis $\mathrm{f}$. sp. tritici pathogen can make previously resistant cultivars become susceptible (Chen et al. 2010; Line and Qayoum 1992) and result in severe disease epidemics and yield losses. New races can spread from one wheat-growing region to another via long-distance transport by wind or human activity. When a race change occurs, the effects of new races on genetic stocks, commercial cultivars, and breeding lines should be determined and new sources of resistance to new and predominant races should be sought. Therefore, it is important to continuously monitor changes in pathogen population virulence.

Race analysis of $P$. striiformis $\mathrm{f}$. sp. tritici has been conducted in the United States since the 1960s. Before 2010, P. striiformis f. sp. tritici races were differentiated using a set of wheat cultivars (Chen 2005, 2007; Chen et al. 2002, 2010; Line 2002; Line and Qayoum 1992; Wan and Chen 2012). Wellings et al. (2004) developed a series of $Y r$ gene near-isogenic lines, thus providing better tools for differentiating $P$. striiformis f. sp. tritici races. We selected wheat lines from the near-isogenic lines and lines developed in our program to establish a set of $18 Y r$ single-gene lines to differentiate $P$. striiformis f. sp. tritici races (Wan and Chen 2014). In 2010, we identified 41 races and named them using a PSTv series and an octal system. This new system for $P$. striiformis f. sp. tritici race analysis has proven to be more informative. Compared with the previous set of cultivar differentials, the new differentials can provide information on virulences and avirulences directly corresponding to individual resistance genes, which is more useful for breeding and disease management programs. We also tested isolates of PSTv races on seven supplementary differentials for comparison with published results of $P$. striiformis $\mathrm{f}$. sp. tritici virulences in other countries (Wan and Chen 2014). In addition, we tested isolates of PSTv races on the previous set of 20 wheat cultivar differentials for comparison with previously identified races named using the PST series. 
Following a widespread epidemic throughout the country in 2010 (Wan and Chen 2014), stripe rust continued to cause damage in 2011 and 2012. In 2011, stripe rust was reported in 20 states. The pathogen was active much earlier and, consequently, disease was severe in the Pacific Northwest (PNW) but stripe rust was relatively low in the other regions (Fig. 1). In the PNW, late-maturing 2010 spring wheat fields provided urediniospore inoculum into the fall, and unusually high precipitation in September and October allowed widespread and unusually heavy infection of winter wheat fields before the onset of cold temperatures. In our stripe rust monitoring in November 2010 , sporulating rust foci up to several meters in diameter were observed in many wheat fields in south-central and central Washington. Although sporulation was not observed in autumn, the majority of the winter wheat fields further east in Washington, northern Idaho, and eastern Oregon were infected before the winter as sporulation was widely observed in March 2011. The relatively mild weather conditions during the winter, plus deep snow cover during the cold spells, allowed the stripe rust fungus to overwinter well. Active stripe rust was observed during the disease surveys in January and February 2011 in the fields with previously observed sporulation. By March 2011, stripe rust was observed throughout the PNW and fungicide application began. Due to the cool and wet weather conditions up to the middle of July, stripe rust continued developing rapidly and had a much longer than normal disease season. Under the long, cool, and wet conditions, the inoculum load was extremely high throughout the wheat-growing season, which reduced the effectiveness of the various levels of high-temperature adult-plant (HTAP) resistance in most wheat cultivars grown in the PNW (Chen 2014). In the PNW, about $80 \%$ of the wheat acreage was sprayed with at least one application of fungicides. Many fields were sprayed twice, and some even three times. In our experimental fields near Pullman, the susceptible winter wheat check ('PS 279') had yield loss of more than $90 \%$ and commercially grown cultivars had yield losses ranged from 0 to $43 \%$. When adjusted by acreages of individual cultivars grown in that year in Washington State, the average yield loss was 18\% (Chen 2014; http://striperust.wsu.edu). In our spring wheat experimental plots planted with a susceptible check variety ('Lemhi') and major cultivars grown in the PNW, Lemhi had $45 \%$ yield loss and the commercial cultivars had 1.5 to $34 \%$ yield losses, with an acreage-adjusted average of $8.6 \%$ (Chen 2014; http://striperust.wsu.edu). In California, severe stripe rust occurred in Sacramento and San Joaquin Valleys and the surrounding areas. Fungicides were extensively applied in wheat fields to reduce damage. In contrast, stripe rust was low in most wheat-growing regions east of the Rocky Mountains due to drought conditions. In 2011, considerable yield losses were estimated for California (6\%), Idaho (7\% on winter wheat and $4 \%$ on spring wheat), Montana (10 and 5\%), Oregon (7 and 7\%), and Washington (3.5 and 2.5\%). In addition to common wheat, $5 \%$ yield loss on durum wheat was recorded in Montana (http://www.ars.usda. gov/main/docs.htm?docid=10123). It was estimated that stripe rust caused $1.76 \%$ loss of yield across the country, or over $35,252,450$ bushels $(959,416$ metric tons $[\mathrm{t}])$ of grain, worth more than $\$ 250$ million, plus millions of dollars spent on chemical control. In Washington State alone, the cost of stripe rust treatment was estimated at about \$28 million for winter wheat and \$12 million for spring wheat. These fungicide treatments saved growers an estimated $\$ 136$ million in winter wheat and \$39 million in spring wheat in 2011 (Chen 2014).

In 2012, stripe rust was widely distributed, occurring in more than 25 states and reaching from the west coast to the east coast and from Texas to North Dakota (Fig. 1). This extensive distribution was similar to that of 2010 (Wan and Chen 2014). Due to the high level of overwintering of $P$. striiformis $\mathrm{f}$. sp. tritici, stripe rust was reported as early as late January in Arkansas and Mississippi. The disease was reported on 1 March in Texas. Several storms and tornadoes in March and April spread P. striiformis f. sp. tritici urediniospores to states further north and east. Overall, in the south-central and Great Plains states, stripe rust was more severe and widespread in 2012 than in 2011, particularly in Oklahoma, Kansas, Mississippi, Colorado, Nebraska, North Dakota, and Minnesota. In the PNW, however, the 2012 epidemic was not as severe as in 2011 (Fig. 1). In 2012, the percentage of yield loss was estimated as $4.0 \%$ in Colorado, $5.7 \%$ in Kansas, and $5.0 \%$ in Mississippi and Oklahoma on winter wheat (http://www.ars.usda.gov/main/docs.htm?docid=10123). Nationwide, the yield loss was estimated as $2.41 \%$ or $1,491,252$ $\mathrm{t}(54,794,060$ bushes $)$, adding to the list of years with losses exceeding 1 million t since 2000: 2001 (1,081,903 t), 2003 (2,418,950 t), 2005 $(2,004,234 \mathrm{t})$, and 2010 (2,606,401 t) (http://striperust.wsu.edu). Without spending millions of dollars on fungicide control, the yield loss figure in 2012 would have been two or three times higher.

The objectives of this study were to (i) identify $P$. striiformis $\mathrm{f}$. sp. tritici races in the United States, (ii) determine their distribution and frequency in 2011 and 2012, and (iii) compare these figures with those of 2010. The results will improve our understanding of stripe rust epidemiology and inform breeding programs developing wheat cultivars with resistance to current and possible future races.

\section{Materials and Methods}

Stripe rust survey and sample collection. Stripe rust was surveyed by the authors in the PNW and by collaborators throughout the United States during the wheat-growing seasons in 2011 and 2012. During the disease-monitoring surveys, samples of $P$. striiformis f. sp. triticiinfected leaves were collected from commercial fields and research nurseries. In general, one or more leaves with uredinia from cultivars, germplasm, or breeding lines in a field were treated as a single sample and put into a glassine or paper bag. When a sample was collected, collection date and location (city, county, and state), host plant, cultivar name or line number, plant growth stage, rust prevalence (percentage of plants infected in the cultivar field or for the entry in a nursery) and severity (percentage of leaf area infected), and IT were recorded for each sample whenever possible. Because the stripe rust fungus can lose viability at high temperatures, the samples were kept as cool as possible and usually sent through overnight
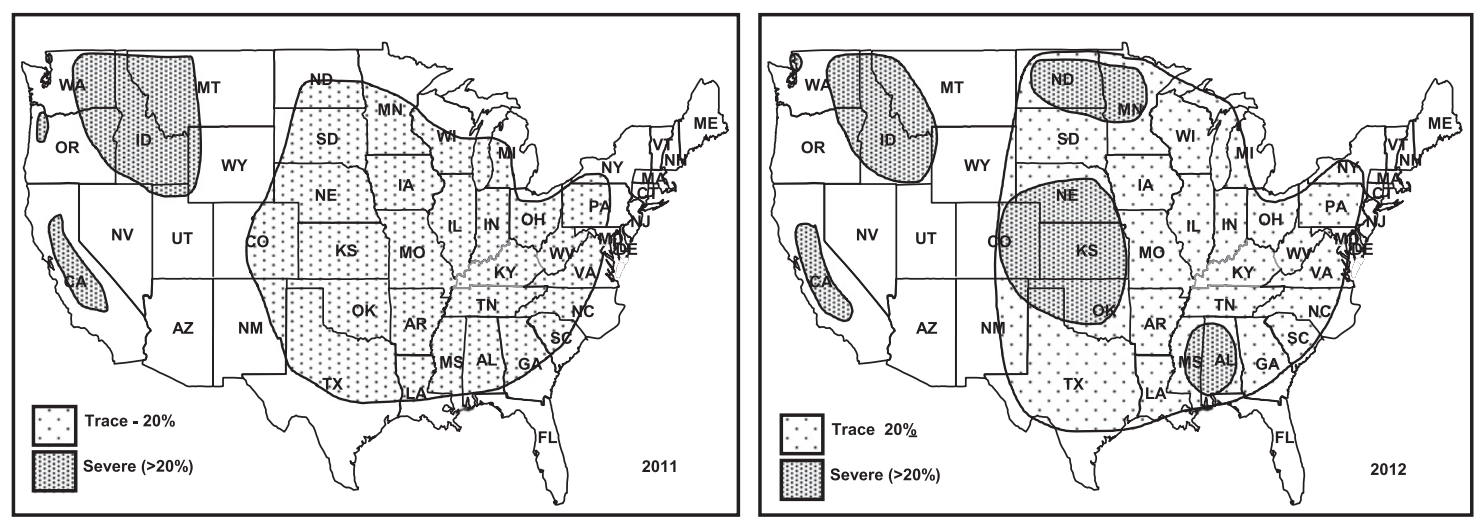

Fig. 1. Occurrence and severity of wheat stripe rust caused by Puccinia striiformis f. sp. tritici in the United States in 2011 and 2012. 
mail to our laboratory. When received, samples were kept in a refrigerator $\left(4^{\circ} \mathrm{C}\right)$ before inoculation to a susceptible wheat cultivar to obtain urediniospore isolates.

Increasing urediniospores and testing on wheat differentials. 'Nugaines' winter wheat, which is susceptible to all $P$. striiformis $\mathrm{f}$. sp. tritici races identified thus far in the United States (Chen et al. 2002, 2010; Line and Qayoum 1992; Wan and Chen 2012, 2014), was used to recover and increase urediniospores from infected leaf samples. Inoculation, growth conditions for the host, and collection and storage of urediniospores were conducted using standard procedures and conditions, as previously described (Chen et al. 2002, 2010; Wan and Chen 2012, 2014). Briefly, seedlings at the twoleaf stage were inoculated with urediniospores from collected samples. Inoculated plants were incubated in a dew chamber at $10^{\circ} \mathrm{C}$ for $24 \mathrm{~h}$ without light and then kept in a growth chamber with a diurnal temperature cycle changing from $4^{\circ} \mathrm{C}$ at $2: 00$ A.M. to $20^{\circ} \mathrm{C}$ at 2:00 P.M. with $16 \mathrm{~h}$ of light. Plants inoculated with urediniospores from individual samples were separated using a booth to avoid contamination. Urediniospores produced on inoculated Nugaines leaves were collected and temporarily stored in a desiccator kept at $4^{\circ} \mathrm{C}$.

For testing on differentials, fresh urediniospores were mixed with talc at a 1:20 ratio to inoculate seedlings at the two-leaf stage. In addition to the set of $18 \mathrm{Yr}$ single-gene line differentials (Wan and Chen 2014), supplemental wheat lines and the previous set of 20 wheat cultivar differentials were also tested for isolates of every new race to provide additional virulence information and for comparison with races previously identified using the old differentials (Chen et al. 2002, 2010; Line and Qayoum 1992; Wan and Chen 2012, 2014). Inoculation and growth of the plants after inoculation were the same as described above. Infection types (IT) were scored at around 20 days after inoculation using a 0-to-9 scale (Line and Qayoum 1992). IT data were converted to avirulence or virulence to describe the virulence-avirulence patterns. An isolate was considered avirulent on a specific differential line when it produced an IT of 0 to 6 or virulent when it produced IT of 7 to 9 (Wan and Chen 2014). If the differential test data indicated the possibilities of either a mixture of two previously identified races or a new race with combined virulences for a sample, multiple subisolates were obtained from individual differentials and the spores were multiplied on the differentials and tested on the set of differentials again. To confirm new virulence patterns, tests were repeated. For a potential new race, a singleuredinium isolate was obtained, increased, and tested on the $\mathrm{Yr}$ single-gene differentials, supplementary lines, and the old cultivar differentials. After inoculating the differentials, the remaining urediniospores of an isolate were dried in a desiccator kept at $4^{\circ} \mathrm{C}$ for

Table 1. Revised key for designating octal codes (OC) and binary codes (BC) for races of Puccinia striiformis f. sp. tritici

\begin{tabular}{|c|c|c|c|c|c|c|}
\hline \multirow[b]{8}{*}{ Previous OC $^{b}$} & \multicolumn{4}{|c|}{ Differential $^{\mathbf{a}}$} & \multirow[b]{8}{*}{ Modified OC } & \multirow[b]{8}{*}{ BC } \\
\hline & \multirow{2}{*}{$\frac{\text { Set }}{1}$} & \multicolumn{3}{|c|}{$Y r$ gene } & & \\
\hline & & Yr1 & Yr5 & Yr6 & & \\
\hline & 2 & $Y r 7$ & Yr8 & $\operatorname{Yr} 9$ & & \\
\hline & 3 & Yr10 & Yr15 & Yr17 & & \\
\hline & 4 & Yr24 & Yr27 & Yr32 & & \\
\hline & 5 & Yr43 & Yr44 & YrSP & & \\
\hline & 6 & $\operatorname{YrTr} 1$ & YrExp2 & YrTye & & \\
\hline 0 & $\ldots$ & A & A & A & 0 & 0 \\
\hline 3 & $\ldots$ & A & A & $\mathrm{V}$ & 1 & 1 \\
\hline 2 & $\ldots$ & A & $\mathrm{V}$ & A & 2 & 10 \\
\hline 6 & $\ldots$ & A & V & V & 3 & 11 \\
\hline 1 & $\ldots$ & $\mathrm{V}$ & A & A & 4 & 100 \\
\hline 5 & $\ldots$ & V & A & V & 5 & 101 \\
\hline 4 & $\ldots$ & V & V & A & 6 & 110 \\
\hline 7 & $\ldots$ & V & V & V & 7 & 111 \\
\hline
\end{tabular}

${ }^{a} \mathrm{~A}=$ avirulent and $\mathrm{V}=$ virulent.

b See Wan and Chen (2014) for the previous octal numbers. The changed codes resulted from the modification are marked in bold. several days before storing for the short term (up to 4 months) at $4^{\circ} \mathrm{C}$ or the long term in liquid nitrogen.

Race identification, frequency, and distribution. The race of each isolate was identified based on its virulence-avirulence patterns on the $18 \mathrm{Yr}$ single-gene differentials and the code of the race was determined using the octal system (Wan and Chen 2014), with modifications as described below. The frequency of a race was calculated within each year. The distributions of detected races were summarized by state, epidemiological region, and the whole country, as previously described (Chen et al. 2010; Wan and Chen 2012, 2014).

Modification of the previously published key for octal codes. The previously published key for octal codes (Wan and Chen 2014) was modified to follow the normal octal notation proposed by others (Gilmour 1973; Habgood 1970; Herrmann et al. 1999; Johnson 1999) (Table 1). The normal octal notation corresponds nicely to a binary notation, which could have an advantage for analysis of races using computerized programs. Because of the modification, we revised the octal codes for the races PSTv-1 to PSTV-41 previously reported by Wan and Chen (2014), and present them together with the new races identified in 2011 and 2012 in Supplementary Table $\mathrm{S} 1$.

Clustering of races. All races identified from 2010 to 2012 were clustered based on the similarity coefficients of the virulence data on the set of $18 \mathrm{Yr}$ single-gene differentials using the unweighted pair group method with the arithmetic means (UPGMA) in the NTSYS program (Rohlf 2008). To each of the $18 \mathrm{Yr}$ genes, virulence was coded as 1 and avirulence as 0, as previously described by Chen et al. (1993). Alternatively, the octal code of a race was expanded to the binary code based on the scheme shown in Table 1, and the binary codes of the races were used in the clustering analysis. An UPGMA tree was generated with the simple match matrix in the SAHN module.

Virulence frequencies and associations. The frequency of a virulence was determined as the percentage of isolates with a specific virulence in each year. Virulence frequencies were classified as high $(>60 \%)$, moderate $(20$ to $60 \%)$, and low $(<20 \%)$. The virulence frequencies for 2011 and 2012 were compared with each other and with 2010 when the new set of $Y r$ single-gene lines were used to differentiate $P$. striiformis f. sp. tritici races for the first time (Wan and Chen 2014). Coefficients of associations between virulences to the $18 \mathrm{Yr}$ genes were calculated based on the virulence-avirulence patterns of the 690 isolates collected in 2011 and 2012 using the formula of Sokal and Rohlf (1995) and the Virulence Analysis Tool program (Herrmann et al. 1999).

\section{Results}

$P$. striiformis f. sp. tritici races identified in 2011 and 2012. In total, 349 isolates were obtained from viable samples collected from 19 states of the United States and one province (Ontario) of Canada in 2011, and 341 isolates were obtained from 24 states of the United States and Ontario, Canada in 2012 (Table 2). From these isolates, 35 races, including 25 previously reported and 10 new races (PSTv-42 to PSTv-51), were identified in 2011; and 23 races, including 4 new races (PSTv-52, PSTv-53, PSTv-64, and PSTv71 ), were identified in 2012 (Table 3). Eighteen races were detected in both 2011 and 2012, including four races (PSTv-43, PSTv-46, PSTV-47, and PSTV-48) that were first detected in 2011. In the total of 40 different races that were detected in the 2 years, the number of virulences ranged from 0 (PSTv-18) to 16 (PSTv-51). PSTv-51, one of the new races identified in 2011, was virulent to all $Y r$ singlegene lines used as differentials, except those with $\operatorname{Yr} 5$ and $\operatorname{Yr} 15$. All other new races had virulence-avirulence patterns similar to some of the previously identified races.

Race frequency and distribution. Nationally, the frequencies of the races detected in 2011 ranged from $0.3 \%$ (only one isolate) to $35.5 \%$; and those of the races detected in 2012 ranged from 0.3 to $47.5 \%$ (Table 3). In 2011, five predominant races were PSTv-11 (35.5\%), PSTv-37 (12.6\%), PSTv-14 (11.8\%), PSTv-4 (5.4\%), and PSTV-34 (3.4\%); the other 30 races had frequencies below $3.5 \%$. In 2012, five predominant races were PSTv-37 (47.5\%), PSTv-11 (11.7\%), PSTv-14 (10.0\%), PSTv-52 (9.4\%), and PSTv-48 (4.4\%); 
all other races were below $3.0 \%$. The changes in frequencies for the predominant races are shown in Figure 2. Compared with the frequencies of races in 2010 (Wan and Chen 2014), PSTv-4 and PSTv-14 increased in both 2011 and 2012, PSTv-34 and PSTv-36 decreased in both 2011 and 2012, and PSTv-11 and PSTv-37 varied greatly in frequency, with PSTv-11 increasing in 2011 and decreasing in 2012 while PSTv-37 decreased in 2011 but increased in 2012. The frequency fluctuations were related to the different severity levels of stripe rust in these 3 years and the distributions of the races (see below).
Different numbers of races were detected in different locations (Table 2). The number of races ranged from 1 in Georgia, Kentucky, Mississippi, and Nebraska to 24 in Washington in 2011; and 1 in Colorado, Georgia, Kentucky, Minnesota, Mississippi, and Ontario to 13 in Washington in 2012. Generally, Washington, Oregon, Idaho, and Californian had relatively high numbers of races compared with other states. Race PSTV-37 was the most widely distributed race. Except for Indiana and Utah, it was detected in all states and Ontario in both 2011 and 2012 or in one of these years. In contrast, PSTv-4, PSTv-11, PSTv-14, and PSTv-48 were detected from only the

Table 2. Number of isolates and number of races of Puccinia striiformis f. sp. tritici identified and their frequencies in various locations in 2011 and 2012

\begin{tabular}{|c|c|c|c|c|c|c|}
\hline \multirow[b]{2}{*}{ State } & \multicolumn{3}{|r|}{2011} & \multicolumn{3}{|r|}{2012} \\
\hline & Isolates & Races & Race (number of isolates) & Isolates & Races & Race (number of isolates) \\
\hline Arkansas & 5 & 3 & PSTv-35(1), PSTv-36(1), PSTv-37(3) & 11 & 4 & PSTv-14(2), PSTv-34(2), PSTv-37(6), PSTv-39(1) \\
\hline California & 63 & 11 & $\begin{array}{l}\text { PSTv-11(19), PSTv-14(4), PSTv-30(8), } \\
\text { PSTv-31(3), PSTv-32(1), PSTv-33(2), } \\
\text { PSTv-34(6), PSTv-35(3), PSTv-36(1), } \\
\text { PSTv-37(15), PSTv-47(1) }\end{array}$ & 30 & 10 & $\begin{array}{l}\text { PSTv-11(9), PSTv-14(1), PSTv-17(1), PSTv-28(1), } \\
\text { PSTv-32(1), PSTv-34(1), PSTv-35(1), } \\
\text { PSTv-36(1), PSTv-37(13), PSTv-52(1) }\end{array}$ \\
\hline Colorado & $\ldots$ & $\ldots$ & $\ldots$ & 2 & 1 & PSTv-37(2) \\
\hline Georgia & 1 & 1 & PSTv-34(1) & 1 & 1 & PSTv-37(1) \\
\hline Idaho & 54 & 12 & $\begin{array}{l}\text { PSTv-4(3), PSTv-11(32), PSTv-14(3), } \\
\text { PSTv-17(2), PSTv-18(1), PSTv-37(1), } \\
\text { PSTv-40(1), PSTv-41(3), PSTv-46(1), } \\
\text { PSTv-49(4), PSTv-50(1), PSTv-51(2) }\end{array}$ & 8 & 6 & $\begin{array}{l}\text { PSTv-11(1), PST-46(1), PSTv-47(1), PSTv-48(3), } \\
\text { PSTv-52(1), PSTv-53(1) }\end{array}$ \\
\hline Illinois & 2 & 2 & PSTv-31(1), PSTv-37(1) & 5 & 2 & PSTv-37(4), PSTv-52(1) \\
\hline Indiana & 2 & 2 & PSTv-28(1), PSTv-30(1) & 0 & 0 & - \\
\hline Kansas & 6 & 2 & PSTv-31(3), PSTv-37(3) & 27 & 9 & $\begin{array}{l}\text { PSTv-11(1), PSTv-14(1), PSTv-28(2), PSTv-30(2), } \\
\text { PSTv-31(1), PSTv-35(3), PSTv-37(13), } \\
\text { PSTv-47(1), PSTv-52(3) }\end{array}$ \\
\hline Kentucky & 1 & 1 & PSTv-37(1) & 1 & 1 & PSTv-37(1) \\
\hline Louisiana & 6 & 3 & PSTv-33(2), PSTv-34(1), PSTv-37(3) & 3 & 2 & PSTv-11(1), PSTv-37(2) \\
\hline Minnesota & 3 & 1 & PSTv-37(3) & 1 & 1 & PSTv-52(1) \\
\hline Missouri & 2 & 2 & PSTv-31(1), PSTv-37(1) & 14 & 3 & PSTv-28(1), PSTv-37(12), PSTv-52(1) \\
\hline Mississippi & 1 & 1 & PSTv-37(1) & 7 & 1 & PSTv-37(7) \\
\hline Montana & 21 & 5 & $\begin{array}{l}\text { PSTv-11(6), PSTv-14(7), PSTv-17(1), } \\
\text { PSTv-31(1), PSTv-37(6) }\end{array}$ & 11 & 4 & PSTv-11(3), PSTv-37(4), PSTv-40(2), PSTv-52(2) \\
\hline North Dakota & 0 & 0 & $\ldots$ & 18 & 2 & PSTv-37(9), PSTv-52(9) \\
\hline Nebraska & 1 & 1 & PSTv-37(1) & 11 & 3 & PSTv-28(1), PSTv-37(9), PSTv-52(1) \\
\hline New York & 0 & 0 & $\ldots$ & 2 & 2 & PSTv-37(1), PSTv-52(1) \\
\hline Oklahoma & 0 & 0 & $\ldots$ & 11 & 2 & PSTv-37(10), PSTv-52(1) \\
\hline Ontario & 3 & 1 & PSTv-37(3) & 1 & 1 & PSTv-52(1) \\
\hline Oregon & 13 & 8 & $\begin{array}{l}\text { PSTv-4(2), PSTv-11(4), PSTv-13(1), } \\
\text { PSTv-39(2), PSTv-41(1), PSTv-44(1), } \\
\text { PSTv-45(1), PSTv-46(1) }\end{array}$ & 11 & 6 & $\begin{array}{l}\text { PSTv-4(1), PSTv-11(4), PSTv-135(1), PSTv-36(1), } \\
\text { PSTv-37(3), PSTv-52(1) }\end{array}$ \\
\hline South Dakota & 0 & 0 & $\ldots$ & 2 & 2 & PSTv-37(1), PSTv-52(1) \\
\hline Texas & 3 & 1 & PSTv-34(3) & 28 & 3 & PSTv-11(4), PSTv-14(2), PSTv-37(22) \\
\hline Utah & 8 & 5 & $\begin{array}{l}\text { PSTv-3(1), PSTv-4(1), PSTv-11(3), } \\
\text { PSTv-14(2), PSTv-46(1) }\end{array}$ & 0 & 0 & $\ldots$ \\
\hline Virginia & 2 & 2 & PSTv-34(1), PSTv-37(1) & 10 & 4 & PSTv-30(1), PSTv-35(1), PSTv-37(6), PSTv-52(2) \\
\hline Washington & 152 & 24 & $\begin{array}{l}\text { PSTv-1(1), PSTv-2(1), PSTv-3(4), PSTv-4(13), } \\
\text { PSTv-5(2), PSTv-8(3), PSTv-11(60), } \\
\text { PSTv-13(1), PSTv-14(25), PSTv-17(5), } \\
\text { PSTv-18(1), PSTv-21(1), PSTv-37(1), } \\
\text { PSTv-38(1), PSTv-39(3), PSTv-40(1), } \\
\text { PSTv-41(4), PSTv-42(6), PSTv-43(9), } \\
\text { PSTv-44(2), PSTv-46(3), PSTv-47(3), } \\
\text { PSTv-48(1), PSTv-49(1) }\end{array}$ & 120 & 13 & $\begin{array}{l}\text { PSTv-4(8), PSTv-11(17), PSTv-14(27), } \\
\text { PSTv-19(1), PSTv-37(33), PSTv-43(2), } \\
\text { PSTv-46(3), PSTv-47(1), PSTv-48(12), } \\
\text { PSTv-52(3), PSTv-53(11), PSTv-64(1), } \\
\text { PSTv-71(1) }\end{array}$ \\
\hline Wisconsin & 0 & 0 & $\ldots$ & 6 & 3 & PSTv-14(1), PSTv-37(3), PSTv-52(2) \\
\hline Total & 349 & 35 & $\begin{array}{l}\text { PSTv-1(1), PSTv-2(1), PSTv-3(5), PSTv-4(19), } \\
\text { PSTv-5(2), PSTv-8(3), PSTv-11(124), } \\
\text { PSTv-13(2), PSTv-14(41), PSTv-17(8), } \\
\text { PSTv-18(2), PSTv-21(1), PSTv-28(1), } \\
\text { PSTv-30(9), PSTv-31(9), PSTv-32(1), } \\
\text { PSTv-33(4), PSTv-34(12), PSTv-35(4), } \\
\text { PSTv-36(2), PSTv-37(44), PSTv-38(1), } \\
\text { PSTv-39(5), PSTv-40(2), PSTv-41(8), } \\
\text { PSTv-42(6), PSTv-43(9), PSTv-44(3), } \\
\text { PSTv-45(1), PSTv-46(6), PSTv-47(4), } \\
\text { PSTv-48(1), PSTv-49(5), PSTv-50(1), } \\
\text { PSTv-51(2) }\end{array}$ & 341 & 23 & $\begin{array}{l}\text { PSTv-4(9), PSTv-11(4), PSTv-14(34), PSTv-17(1), } \\
\text { PSTv-19(1), PSTv-28(5), PSTv-30(3), } \\
\text { PSTv-31(1), PSTv-32(1), PSTv-34(3), } \\
\text { PSTv-35(6), PSTv-36(2), PSTv-37(162), } \\
\text { PSTv-39(1), PSTv-40(2), PSTv-43(2), } \\
\text { PSTv-46(4), PSTv-47(3), PSTv-48(15), } \\
\text { PSTv-52(32), PSTv-53(12), PSTv-64(1), } \\
\text { PSTv-71(1) }\end{array}$ \\
\hline
\end{tabular}


western states, except one isolate each of PSTv-11 and PSTv-14 that was detected in Kansas in 2012.

Of the 12 epidemiological regions, region 1 (R1) had the highest number of races, with 24 races in 2011 and 16 races in 2012; followed by R6, with 11 races in 2011 and 10 races in 2012 (Table 4). A moderate number of races were detected in R7 in both $2011(n=5)$ and $2012(n=6)$. Apart from a high number $(n=9)$ of races in R8 in 2012, the number of races in all other regions was low in both years. When the western and eastern regions (including Ontario, Canada) were compared, the western regions (R1 to R6) had more races than the eastern United States (R7 to R12); 34 races were detected in 2011 and 20 races in 2012 in the western regions, while 8 races in 2011 and 11 races in 2012 were detected in the eastern regions. For races that had a significant frequency $(>5 \%)$, the predominant races in the western regions were PSTv-11 (39.9\%), PSTv-14 (13.2\%), PSTv-37 (7.4\%), and PSTv-4 (6.1\%) in 2011 and PSTv-37 (29.4\%), PSTv-11 (18.9\%), PSTv-14 (15.6\%), PSTV-48 (8.3\%), and PSTv-53 (6.7\%) in 2012. For the eastern regions, the predominant races were PSTv-37 (55.3\%), PSTv-34 (15.8\%), PSTV-31 (13.2\%), and PSTv-33 (5.3\%) in 2011 and PSTv-37 (67.7\%) and PSTv-52 (14.9\%) in 2012. Races PSTv-4,
PSTv-11, PSTv-14, PSTv-48, and PSTv-53, which have virulences to $Y r 1$ and YrTye (Table 3), were predominant in the western regions but generally absent in the eastern regions (Table 4).

Race groups. Based on the virulence data, the 55 races, including the 40 races detected in this study and 15 identified in 2010 but not detected in 2011 and 2012, clustered into two major groups, G1 and G2, using the similarity coefficient of 0.6 as a cutoff point (Fig. 3 ). The 20 races in $\mathrm{G} 1$ had relatively narrow virulence spectra. For example, PSTv-18 was virulent to none; PSTv-19 and PSTv-20 were virulent to only one; and PSTv-21, PSTv-22, and PSTv-64 were virulent to two of the $18 \mathrm{Yr}$ single-gene differentials (Table 3). G2 had 35 races that had wide virulence spectra, ranging from 7 (PSTv-43) to 16 (PSTv-51) virulences (Table 3 ). The groups could be further separated into subgroups (G1a, G1b, and G1c in G1 and G2a and G2b in G2) using the similarity coefficient of 0.7 as a cutoff point. Races in G1a and G1c were mostly detected only in the western regions and at low frequencies. Some races in G1b (PSTv-4, PSTv-48, and PSTv-53) had significant frequencies but were also detected only in the western regions. Predominant races (PSTv-11 and PSTv-14) in subgroup G2a mostly occurred in the western regions, while those in G2b (PSTv-37 and PSTv-52)

Table 3. Races of Puccinia striiformis f. sp. tritici detected in the United States in 2011 and 2012 and their octal codes (OC), virulence-avirulence formulae, number of isolates $(N)$, and frequencies

\begin{tabular}{|c|c|c|c|c|c|c|}
\hline \multirow[b]{2}{*}{$\mathbf{O C}^{\mathbf{a}}$} & \multirow[b]{2}{*}{ Race $^{\mathbf{b}}$} & \multirow[b]{2}{*}{ Virulence-avirulence formula ${ }^{\mathbf{b}}$} & \multicolumn{2}{|c|}{2011} & \multicolumn{2}{|c|}{2012} \\
\hline & & & $N$ & Freq. $(\%)$ & $N$ & Freq. $(\%)$ \\
\hline 000000 & PSTv-18 & $/ 1,5,6,7,8,9,10,15,17,24,27,32,43,44$, SP,Tr1,Exp2,Тye & 2 & 0.6 & $\ldots$ & $\ldots$ \\
\hline 100000 & PSTv-19 & 6/1,5,7,8,9,10,15,17,24,27,32,43,44,SP,Tr1,Exp2,Туе & $\ldots$ & $\ldots$ & 1 & 0.3 \\
\hline 101000 & PSTv-21 & $\mathbf{6 , 1 7} / 1,5,7,8,9,10,15,24,27,32,43,44$, ,SP,Tr1,Exp2,Tye & 1 & 0.3 & $\ldots$ & $\ldots$ \\
\hline 110000 & PSTv-64 & $\mathbf{6 , 9} / 1,5,7,8,10,15,17,24,27,32,43,44$, SP,Tr1,Exp2,Tye & $\ldots$ & $\ldots$ & 1 & 0.3 \\
\hline 151022 & PSTv-28 & $\mathbf{6 , 7 , 9 , 1 7 , 4 4 , E x p 2 / 1 , 5 , 8 , 1 0 , 1 5 , 2 4 , 2 7 , 3 2 , 4 3 , S P , T r 1 , T y e ~}$ & 1 & 0.3 & 5 & 1.5 \\
\hline 170026 & PSTv-30 & 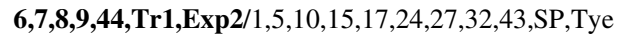 & 9 & 2.6 & 3 & 0.9 \\
\hline 170066 & PSTv-32 & 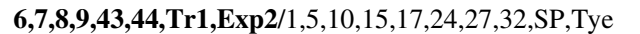 & 1 & 0.3 & 1 & 0.3 \\
\hline 170226 & PSTv-33 & $\mathbf{6 , 7 , 8 , 9 , 2 7 , 4 4 , T r 1 , E x p 2 / 1 , 5 , 1 0 , 1 5 , 1 7 , 2 4 , 3 2 , 4 3 , S P , T y e ~}$ & 4 & 1.2 & .. & $\ldots$ \\
\hline 170266 & PSTv-36 & $\mathbf{6 , 7 , 8 , 9 , 2 7 , 4 3 , 4 4 , T r 1 , E x p 2 / 1 , 5 , 1 0 , 1 5 , 1 7 , 2 4 , 3 2 , S P , T y e ~}$ & 2 & 0.6 & 2 & 0.6 \\
\hline 171026 & PSTv-31 & 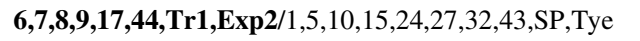 & 9 & 2.6 & 1 & 0.3 \\
\hline 171066 & PSTv-35 & $\mathbf{6 , 7 , 8 , 9 , 1 7 , 4 3 , 4 4 , T r 1 , E x p 2 / 1 , 5 , 1 0 , 1 5 , 2 4 , 2 7 , 3 2 , S P , T y e ~}$ & 4 & 1.2 & 6 & 1.8 \\
\hline 171226 & PSTv-34 & $\mathbf{6 , 7 , 8 , 9 , 1 7 , 2 7 , 4 4 , T r 1 , E x p 2 / 1 , 5 , 1 0 , 1 5 , 2 4 , 3 2 , 4 3 , S P , T y e ~}$ & 12 & 3.4 & 3 & 0.9 \\
\hline 171262 & PSTv-52 & $\mathbf{6 , 7 , 8 , 9 , 1 7 , 2 7 , 4 3 , 4 4 , E x p 2 / 1 , 5 , 1 0 , 1 5 , 2 4 , 3 2 , S P , T r 1 , E x p 2 ~}$ & $\ldots$ & $\ldots$ & 32 & 9.4 \\
\hline 171266 & PSTv-37 & $\mathbf{6 , 7 , 8 , 9 , 1 7 , 2 7 , 4 3 , 4 4 , T r 1 , E x p 2 / 1 , 5 , 1 0 , 1 5 , 2 4 , 3 2 , S P , T y e ~}$ & 44 & 12.6 & 162 & 47.5 \\
\hline 171666 & PSTv-38 & $\mathbf{6 , 7 , 8 , 9 , 1 7 , 2 4 , 2 7 , 4 3 , 4 4 , T r 1 , E x p 2 / 1 , 5 , 1 0 , 1 5 , 3 2 , S P , T y e ~}$ & 1 & 0.3 & $\ldots$ & $\ldots$ \\
\hline 174766 & PSTV-40 & $\mathbf{6 , 7 , 8 , 9 , 1 0 , 2 4 , 2 7 , 3 2 , 4 3 , 4 4 , T r 1 , E x p 2 / 1 , 5 , 1 5 , 1 7 , S P , T y e ~}$ & 2 & 0.6 & 2 & 0.6 \\
\hline 175266 & PSTV-39 & $\mathbf{6 , 7 , 8 , 9 , 1 0 , 1 7 , 2 7 , 4 3 , 4 4 , T r 1 , E x p 2 / 1 , 5 , 1 5 , 2 4 , 3 2 , S P , T y e ~}$ & 5 & 1.4 & 1 & 0.3 \\
\hline 175766 & PSTv-41 & $\mathbf{6 , 7 , 8 , 9 , 1 0 , 1 7 , 2 4 , 2 7 , 3 2 , 4 3 , 4 4 , T r 1 , E x p 2 / 1 , 5 , 1 5 , S P , T y e ~}$ & 8 & 2.3 & $\ldots$ & $\ldots$ \\
\hline 194226 & PSTv-45 & $\mathbf{6 , 7 , 8 , 9 , 1 0 , 2 7 , 4 4 , T r 1 , E x p 2 / 1 , 5 , 1 5 , 1 7 , 2 4 , 3 2 , 4 3 , S P , T y e ~}$ & 1 & 0.3 & $\ldots$ & $\ldots$ \\
\hline 400000 & PSTv-1 & $\mathbf{1} / 5,6,7,8,9,10,15,17,24,27,32,43,44, \mathrm{SP}, \operatorname{Tr} 1, \operatorname{Exp} 2$, Tye & 1 & 0.3 & $\ldots$ & $\ldots$ \\
\hline 470221 & PSTv-43 & $\mathbf{1 , 7 , 8 , 9 , 2 7 , 4 4 , T y e / 5 , 6 , 1 0 , 1 5 , 1 7 , 2 4 , 3 2 , 4 3 , S P , T r 1 , E x p 2 ~}$ & 9 & 2.6 & 2 & 0.6 \\
\hline 470223 & PSTv-44 & $\mathbf{1 , 7 , 8 , 9 , 2 7 , 4 4 , E x p 2 , T y e / 5 , 6 , 1 0 , 1 5 , 1 7 , 2 4 , 3 2 , 4 3 , S P , T r 1 ~}$ & 3 & 0.9 & $\ldots$ & $\ldots$ \\
\hline 471221 & PSTv-42 & $\mathbf{1 , 7 , 8 , 9 , 1 7 , 2 7 , 4 4 , T y e / 5 , 6 , 1 0 , 1 5 , 2 4 , 3 2 , 4 3 , S P , T r 1 , E x p 2 ~}$ & 6 & 1.7 & $\ldots$ & $\ldots$ \\
\hline 471223 & PSTv-8 & $\mathbf{1 , 7 , 8 , 9 , 1 7 , 2 7 , 4 4 , E x p 2 , T y e ~} / 5,6,10,15,24,32,43, \mathrm{SP}, \operatorname{Tr} 1$ & 3 & 0.9 & $\ldots$ & $\ldots$ \\
\hline 510001 & PSTv-48 & $\mathbf{1 , 6 , 9 , T y e} / 5,7,8,10,15,17,24,27,32,43,44, \mathrm{SP}, \operatorname{Tr} 1, \operatorname{Exp} 2$ & 1 & 0.3 & 15 & 4.4 \\
\hline 510011 & PSTv-53 & $\mathbf{1 , 6 , 9 , S P , T y e / 5 , 7 , 8 , 1 0 , 1 5 , 1 7 , 2 4 , 2 7 , 3 2 , 4 3 , 4 4 , T r 1 , E x p 2 ~}$ & $\ldots$ & $\ldots$ & 12 & 3.5 \\
\hline 511001 & PSTv-2 & $\mathbf{1 , 6 , 9 , 1 7 , T y e} / 5,7,8,10,15,24,27,32,43,44, \mathrm{SP}, \operatorname{Tr} 1, \operatorname{Exp} 2$ & 1 & 0.3 & $\ldots$ & $\ldots$ \\
\hline 511201 & PSTv-46 & $\mathbf{1 , 6 , 9 , 1 7 , 2 7 , T y e / 5 , 7 , 8 , 1 0 , 1 5 , 2 4 , 3 2 , 4 3 , 4 4 , S P , T r 1 , E x p 2 ~}$ & 6 & 1.7 & 4 & 1.2 \\
\hline 511211 & PSTv-4 & $\mathbf{1 , 6 , 9 , 1 7 , 2 7 , S P , T y e ~} / 5,7,8,10,15,24,32,43,44, \operatorname{Tr} 1, \operatorname{Exp} 2$ & 19 & 5.4 & 9 & 2.6 \\
\hline 531201 & PSTv-3 & $\mathbf{1 , 6 , 8 , 9 , 1 7 , 2 7 , T y e / 5 , 7 , 1 0 , 1 5 , 2 4 , 3 2 , 4 3 , 4 4 , S P , T r 1 , E x p 2 ~}$ & 5 & 1.4 & $\ldots$ & $\ldots$ \\
\hline 550263 & PSTv-71 & $\mathbf{1 , 6 , 7 , 9 , 2 7 , 4 3 , E x p 2 , T y e} / 5,8,10,15,17,24,32,44, \mathrm{SP}, \operatorname{Tr} 1$ & $\ldots$ & $\ldots$ & 1 & 0.3 \\
\hline 571220 & PSTV-5 & $\mathbf{1 , 6 , 7 , 8 , 9 , 1 7 , 2 7 , 4 4 / 5 , 1 0 , 1 5 , 2 4 , 3 2 , 4 3 , S P , T r 1 , E x p 2 , T y e ~}$ & 2 & 0.6 & $\ldots$ & $\ldots$ \\
\hline 571263 & PSTv-11 & $\mathbf{1 , 6 , 7 , 8 , 9 , 1 7 , 2 7 , 4 3 , 4 4 , E x p 2 , T y e / 5 , 1 0 , 1 5 , 2 4 , 3 2 , S P , T r 1 ~}$ & 124 & 35.5 & 40 & 11.7 \\
\hline 571266 & PSTv-47 & $\mathbf{1 , 6 , 7 , 8 , 9 , 1 7 , 2 7 , 4 3 , 4 4 , T r 1 , E x p 2 / 5 , 1 0 , 1 5 , 2 4 , 3 2 , S P , T y e ~}$ & 4 & 1.2 & 3 & 0.9 \\
\hline 571267 & PSTv-14 & $\mathbf{1 , 6 , 7 , 8 , 9 , 1 7 , 2 7 , 4 3 , 4 4 , T r 1 , E x p 2 , T y e / 5 , 1 0 , 1 5 , 2 4 , 3 2 , S P ~}$ & 41 & 11.8 & 34 & 10.0 \\
\hline 571271 & PSTv-13 & $\mathbf{1 , 6 , 7 , 8 , 9 , 1 7 , 2 7 , 4 3 , 4 4 , S P , T y e / 5 , 1 0 , 1 5 , 2 4 , 3 2 , T r 1 , E x p 2 ~}$ & 2 & 0.6 & $\ldots$ & $\ldots$ \\
\hline 571273 & PSTv-17 & $\mathbf{1 , 6 , 7 , 8 , 9 , 1 7 , 2 7 , 4 3 , 4 4 , S P , E x p 2 , T y e / 5 , 1 0 , 1 5 , 2 4 , 3 2 , T r 1 ~}$ & 8 & 2.3 & 1 & 0.3 \\
\hline 575277 & PSTv-50 & $\mathbf{1 , 6 , 7 , 8 , 9 , 1 0 , 1 7 , 2 7 , 4 3 , 4 4 , S P , T r 1 , E x p 2 , T y e / 5 , 1 5 , 2 4 , 3 2 ~}$ & 1 & 0.3 & $\ldots$ & $\ldots$ \\
\hline 575767 & PSTv-49 & 1,6,7,8,9,10,17,24,27,32,43,44,Tr1,Exp2,Tye/5,15,SP & 5 & 1.4 & $\ldots$ & $\ldots$ \\
\hline 575777 & PSTv-51 & 1,6,7,8,9,10,17,24,27,32,43,44,SP,Tr1,Exp2,Туе/5,15 & 2 & 0.6 & $\ldots$ & $\ldots$ \\
\hline
\end{tabular}

a OC and virulence-avirulence formulae for the $18 \mathrm{Yr}$ genes were based on the methods of Wan and Chen (2014), with modifications (see the text).

b New races identified in 2011 and 2012 are highlighted in bold. 
were predominant in the eastern regions but also occurred in the western regions.

Virulence frequencies, distributions, and associations. In 2011, nationwide percentages of virulences to $\operatorname{Yr} 6, \operatorname{Yr} 7, \operatorname{Yr} 8, \operatorname{Yr} 9, \operatorname{Yr} 17$, $Y r 27, Y r 43, Y r 44, Y r T r 1$, and $Y r E x p 2$ were high (64.2 to $99.7 \%$; Fig. 4), and these virulences were detected in all 12 epidemic regions and almost all of the states from which viable samples were obtained (Tables 3 and 4). The frequencies of these virulences ranged from 44.1\% ( $Y r T r 1$ in 2011) to 99.7\% ( $Y r 6$ and $Y r 9$ ) in 2012. Except for high frequencies in 2011, the frequencies of virulences to $Y r 1$ and YrTye were moderate (22.0 to $34.6 \%$; Fig. 4). These two virulences were detected only in the western United States (R1 to R6) in 2011. In 2012, these two virulences were detected in the eastern regions (R7 to R12) but at low frequencies, indicating that races with these virulences were spreading from the western to the eastern regions. Virulences to $\operatorname{Yr} 10, \operatorname{Yr} 24, \mathrm{Yr} 32$, and $\mathrm{YrSP}$ were low (0.6 to $5.7 \%$; Fig. 4), and were mostly detected in the western regions (R1 to R6) (Table 4). Specifically, virulence to $\mathrm{Yr} 10$ was detected only in R1 in both 2011 and 2012 and R3 in 2012, except for one sample from Arkansas in 2012. Similarly, virulences to $\mathrm{Yr} 24$ and $\mathrm{Yr} 32$ were only found in R1 in 2011 and 2012 and R3 in 2012. Virulence to $\operatorname{YrSP}$ was detected only in R1 in both 2011 and 2012 and R3 and R6 in 2012. Virulence to $\mathrm{Yr} 17$ was common in both 2011 (90.0\%) and $2012(88.9 \%)$ across the country. Specifically, the frequency of the $\mathrm{Yrl}$ virulence was $90.0 \%$ in 2011 and $80.6 \%$ in 2012 in the western regions, and $89.5 \%$ in 2011 and $98.1 \%$ in 2012 in the eastern regions.

Based on the comparison of the frequencies of virulences from 2010 to 2012, virulences to $\operatorname{Yr} 6, \operatorname{Yr} 7, \operatorname{Yr} 8, \operatorname{Yr} 9, \operatorname{Yr} 17, \operatorname{Yr} 27, \operatorname{Yr} 43$, $Y r 44$, and $Y r E x p 2$ remained at relatively stable and high frequencies (Fig. 4). Virulences to $\mathrm{Yr} 10, \mathrm{Yr} 24, \mathrm{Yr} 32$, and $\mathrm{YrSP}$ remained at relatively stable but low frequencies. Significant frequency changes were identified for virulences $Y r 1, Y r T r 1$, and $Y r T y e$ because virulences to $\mathrm{Yrl}$ and YrTye increased significantly in 2011 but then deceased in 2012; and virulence to $\operatorname{YrTr} 1$ decreased significantly in 2011 from 2010 but then increased in 2012. Virulences to $\operatorname{Yr} 5$ and $Y r 15$ were not detected, indicating that these two genes were still effective against all races identified thus far in the United States.

Highly positive associations $(>0.60)$ were identified between virulences to $Y r 1$ and $Y r T y e ; Y r 7$ and $Y r E x p 2, Y r 44, Y r 43$, or $Y r 8$; $Y r 8$ and $Y r E x p 2, Y r 44$, or $Y r 43 ; Y r 10$ and $Y r 32$ or $Y r 24 ; Y r 24$ and $Y r 32$; Yr43 and YrExp2 or Yr44; and Yr44 and YrExp2 (Table 5). Negative associations (disassociation, $<0$ ) were found between virulences to Yr1 or YrTye and $Y r 6, Y r 7, Y r 8, Y r 10, Y r 17, Y r 24, Y r 32, Y r 43$, $Y r 44, Y r T r 1$, or $Y r E x p 2 ; Y r S P$ and $Y r 7, Y r 8, Y r 17, Y r 27, Y r 43$, $Y r 44, Y r E x p 2$, or $Y r T r 1$; and $Y r 17$ and $Y r 10, Y r 24$, or $Y r 32$. Because none of the isolates was virulent to $Y r 5$ and $Y r 15$, the avirulences to these two genes were highly associated (1.00), and they were not associated $(0.00)$ with any other avirulences or virulences among those to the $18 \mathrm{Yr}$ genes. The remaining pairwise associations were positive but not high (0.01 to 0.58$)$.

Virulences of new races on supplementary and old cultivar differentials. All of the 14 new races (PSTv-42 to PSTv-53, PSTv64, and PSTv-71) were virulent to $Y r 2$ ('Kalyansona') and $Y r 28$ ('AvSYr28NIL'). All of the races, except PSTv-71, were virulent to $Y r 25$ ('Hugenoot'), Yr31 ('AvSYr31NIL'), and YrA ('AvSYrANIL'). Except for races PSTV-53 and PSTV-71, all of the new races were avirulent on 'Hybrid 46' ( $\mathrm{Yr} 4$ and $\mathrm{YrH} 46$ ). Five of the races (PSTv-43, PSTv-46, PSTv-47, PSTv-48, and PSTv-51) were avirulent on 'Vilmorin 23' ( $Y r 3$ and $Y r V 23)$.

When tested on the old set of 20 wheat cultivar differentials, all of these 14 new races were virulent on Lemhi (Yr21), 'Heines VII' (Yr2 and $\mathrm{YrHVII}$ ), 'Stephens' (Yr3a, YrS, and YrSte), and 'AvSYr9NIL' $(\mathrm{Yr} 9)$. Isolates of PSTv-42 were identified as PST-142; PSTv-43 and PSTv-44 as PST-153; PSTv-45 as PST-130; PSTv-46 as PST144; PSTv-47 as PST-147; PSTv-48, PSTv-53, and PSTv-71 as PST-149; PSTv-49 and PSTv-51 as PST-151; PSTv-50 as PST152; PSTV-52 as PST-150; and PSTV-64 as PST-71. Five races, PST-149 to PST-153, were identified for the first time in this study using the old differentials.

\section{Discussion}

In 2011, stripe rust was extremely severe in the western regions, especially the PNW (Chen 2014). The highest potential yield loss $(>90 \%)$ on susceptible winter wheat varieties was recorded in experimental fields (http://striperust.wsu.edu). The extremely severe epidemic resulted in wide use of fungicides. The disease was more severe in 2011 than 2012. In 2012, susceptible winter wheat varieties had up to $57 \%$ yield loss and susceptible spring wheat varieties had up to $49 \%$ yield loss (http://striperust.wsu.edu). The extremely severe epidemic in the PNW was attributed to heavy inoculum in the fall of 2010 due to the prolonged 2010 stripe rust season, wet conditions conductive to infection in the fall, a relatively mild winter with deep snow cover during the cold periods to allow P. striiformis $\mathrm{f}$. sp. tritici to survive well, and cool and wet conditions during the late spring and summer of 2011 for continual spore production and infection (Chen 2011; 2014). The low temperature and high moisture conditions during the late spring and early summer of 2011 were extremely favorable for infection and disease development and reduced effectiveness of HTAP resistance. Changes in acreage of major cultivars, especially the increase of cultivars with herbicide resistance but less resistance to stripe rust, contributed to the severe epidemic (Chen 2011).

In the eastern regions, however, stripe rust was more severe in 2012 than in 2011; however, the epidemics of these 2 years were less severe than the epidemic in 2010 (Wan and Chen 2014). The less severe stripe rust in 2011 was mainly due to drought in the southcentral states and the middle of the Great Plains. The relatively severe epidemic in 2012 was due to the large amount of overwintered inoculum in the south-central states (R7), quick spread of inoculum from $\mathrm{R} 7$ to other regions to the north and east, and relatively stripe-rustfavorable temperature and moisture conditions. Although in low frequencies, the appearance of races such as PSTv-11 and PSTv-14, which had been predominant in the western regions (Wan and Chen 2014), could have contributed to the epidemic in the eastern regions in 2012 .

The numbers of samples from the western and eastern regions were related to the disease levels in 2011 and 2012. Especially for the eastern regions, the sample numbers reflected the severity and scale of the epidemics. In 2011, there were 311 samples from the western regions but only 38 from the eastern regions when stripe rust was extremely severe in the west and less severe in the eastern regions. In contrast, there were 180 samples from the western regions and 161 samples from the eastern regions in 2012, when stripe rust was more severe in the eastern regions than in the western regions. However, regardless of the relative severity levels, more races were identified in the western regions than in the eastern regions. In the

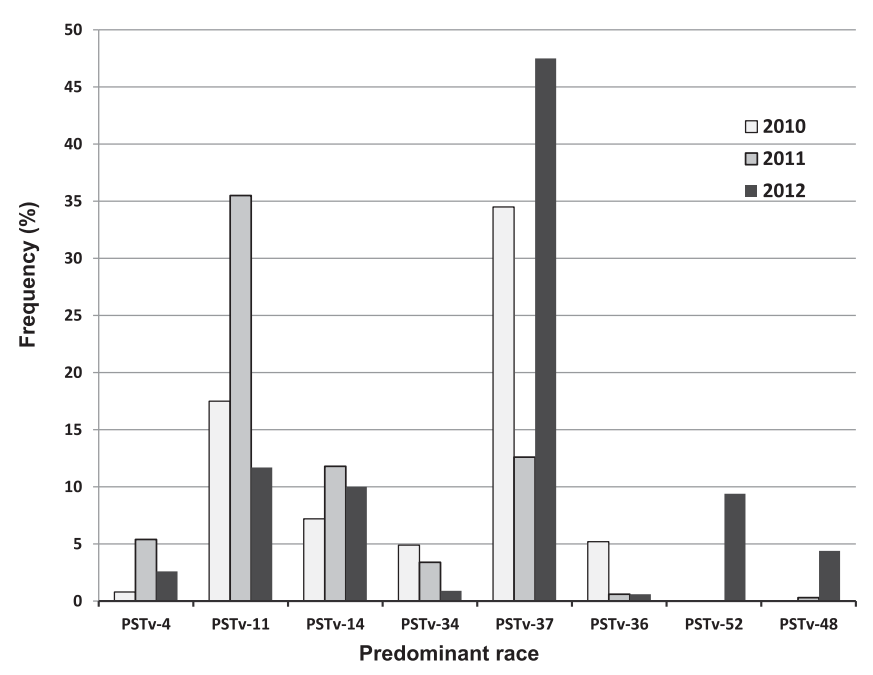

Fig. 2. Frequency changes of predominant Puccinia striiformis f. sp. tritici races in the United States in 2010, 2011, and 2012. 
western regions (R1 to R6), 34 races were identified in 2011 and 20 in 2012 . In contrast, only 8 races were identified in 2011 and only 11 in 2012 in the eastern regions (R7 to R12). The finding of more races in the western than the eastern regions is in agreement with the previous race studies in the United States (Chen 2005, 2007; Chen et al. 2002, 2010; Line 2002; Line and Qayoum 1992; Wan and Chen 2012, 2014). Compared with the eastern United States, the higher race diversity in the western United States is due to more diverse climatic conditions, more diverse types of wheat cultivars, more resistance genes in wheat cultivars, and weather and cropping conditions more favorable for the pathogen survival and disease development (Chen 2014; Chen et al. 2002, 2010; Sharma-Poudyal et al. 2014; Wan and Chen 2012).
Although a large number of races were identified in both 2011 and 2012 , most of the races had low frequencies and, therefore, should contribute less to the epidemics in these years. The major causes of the epidemics in these years were the predominant races. Nationally, the top five predominant races in 2011 were (in order of incidence) PSTv-11, PST-37, PSTv-14, PSTv-4, and PSTv-34, accounting for $68.7 \%$ of the isolates; and those in 2012 were PSTv-37, PSTv-11, PSTv-14, PSTv-52, and PSTv-48, accounting for $78.6 \%$ of the isolates. These seven races can be classified into two groups based on the virulence or avirulence to resistance genes $Y r 1$ and YrTye: PSTv-11, PSTv-14, PSTv-4, and PSTv-48 are virulent while PSTv-37, PSTv-52, and PSTv-34 are avirulent to the two resistance genes. The PSTV-11 group was only detected in the western regions

Table 4. Number of isolates, number of races, and their frequencies (\%) in 12 epidemiological regions in 2011 and $2012^{\mathrm{a}}$

\begin{tabular}{|c|c|c|c|c|c|c|}
\hline \multirow[b]{2}{*}{ Region $^{b}$} & \multicolumn{3}{|r|}{2011} & \multicolumn{3}{|r|}{2012} \\
\hline & Isolates & Races & $\operatorname{Races}(\%)$ & Isolates & Races & Races (\%) \\
\hline $\mathrm{R} 1$ & 154 & 24 & $\begin{array}{l}\text { PSTv-1(0.7), PSTv-2(0.7), PSTv-3(2.6), } \\
\text { PSTv-4(9.7), PSTv-5(1.3), PSTv-8(2.0), } \\
\text { PSTv-11(38.3), PSTv-13(1.3), PSTv-14(11.0), } \\
\text { PSTv-17(3.9), PSTv-18(0.7), PSTv-37(2.0), } \\
\text { PSTv-38(0.7), PSTv-39(3.3), PSTv-40(0.7), } \\
\text { PSTv-41(3.3), PSTv-42(3.9), PSTv-43(5.8), } \\
\text { PSTv-44(2.0), PSTv-45(0.7), PSTv-46(2.6), } \\
\text { PSTv-47(2.0), PSTv-48(0.7), PSTv-49(0.7) }\end{array}$ & 107 & 16 & $\begin{array}{l}\text { PSTv-4(8.4), PSTv-11(12.2), PSTv-14(0.9), } \\
\text { PSTv-19(0.9), PSTv-35(0.9), PSTv-36(0.9), } \\
\text { PSTv-37(37.4), PSTv-40(1.9), PSTv-43(1.9), } \\
\text { PSTv-46(2.8), PSTv-47(0.9), PSTv-48(14.0), } \\
\text { PSTv-52(3.7), PSTv-53(11.2), PSTv-64(0.9), } \\
\text { PSTv-71(0.9) }\end{array}$ \\
\hline $\mathrm{R} 2$ & 16 & 4 & $\begin{array}{l}\text { PSTv-11(31.3), PSTv-14(37.5), PSTv-31(6.3), } \\
\text { PSTv-37(25.0) }\end{array}$ & 2 & 1 & PSTv-52(100.0) \\
\hline $\mathrm{R} 3$ & 59 & 13 & $\begin{array}{l}\text { PSTv-3(1.7), PSTv-4(6.8), PSTv-11(54.2), } \\
\text { PSTv-14(8.5), PSTv-17(3.4), PSTv-18(1.7), } \\
\text { PSTv-37(1.7), PSTv-40(1.7), PSTv-41(5.1), } \\
\text { PSTv-46(3.4), PSTv-49(6.8), PSTv-50(1.7), } \\
\text { PSTv-51(3.4) }\end{array}$ & 2 & 2 & PSTv-46(50.), PSTv-52(50.0) \\
\hline R4 & - & - & & 2 & 1 & PSTv-11(100.0) \\
\hline $\mathrm{R} 5$ & 19 & 3 & PSTv-11(47.4), PSTv-14(47.4), PSTv-21(5.3) & 37 & 3 & PSTv-11(27.0), PSTv-14(70.3), PSTv-47(2.7) \\
\hline R6 & 63 & 11 & $\begin{array}{l}\text { PSTv-11(30.2), PSTv-14(6.4), PSTv-30(12.7), } \\
\text { PSTv-31(4.8), PSTv-32(1.6), PSTv-33(3.2), } \\
\text { PSTv-34(9.5), PSTv-35(4.8), PSTv-36(1.6), } \\
\text { PSTv-37(23.8), PSTv-47(1.6) }\end{array}$ & 30 & 10 & $\begin{array}{l}\text { PSTv-11(30.0), PSTv-14(3.3), PSTv-17(3.3), } \\
\text { PSTv-28(3.3), PSTv-32(3.3), PSTv-34(3.3), } \\
\text { PSTv-35(3.3), PSTv-36(3.3), PSTv-37(43.3), } \\
\text { PSTv-52(3.3) }\end{array}$ \\
\hline R7 & 14 & 5 & $\begin{array}{l}\text { PSTv-33(14.3), PSTv-34(28.6), PSTv-35(7.1), } \\
\text { PSTv-36(7.1), PSTv-37(42.9) }\end{array}$ & 53 & 6 & $\begin{array}{l}\text { PSTv-11(9.4), PSTv-14(7.6), PSTv-34(3.8), } \\
\text { PSTv-37(75.5), PSTv-39(1.9), PSTv-52(1.9) }\end{array}$ \\
\hline R8 & 7 & 2 & PSTv-31(42.9), PSTv-37(57.1) & 40 & 9 & $\begin{array}{l}\text { PSTv-11(2.5), PSTv-14(2.5), PSTv-28(7.5), } \\
\text { PSTv-30(5.0), PSTv-31(2.5), PSTv-35(7.5), } \\
\text { PSTv-37(60.0), PSTv-47(2.5), PSTv-52(10.0) }\end{array}$ \\
\hline R9 & 3 & 1 & PSTv-37(100.0) & 21 & 2 & PSTv-37(47.6), PSTv-52(52.4) \\
\hline $\mathrm{R} 10$ & 3 & 2 & PSTv-34(33.3), PSTv-37(66.7) & 9 & 1 & PSTv-37(100.0) \\
\hline $\mathrm{R} 11$ & 9 & 4 & $\begin{array}{l}\text { PSTv-28(11.1), PSTv-30(11.1), PSTv-31(22.2), } \\
\text { PSTv-37(55.6) }\end{array}$ & 26 & 4 & $\begin{array}{l}\text { PSTv-14(3.9), PSTv-28(3.9), PSTv-37(73.1), } \\
\text { PSTv-52(19.2) }\end{array}$ \\
\hline $\mathrm{R} 12$ & 2 & 2 & PSTv-34(50.0), PSTv-37(50.0) & 12 & 4 & $\begin{array}{l}\text { PSTv-30(8.3), PSTv-35(8.3), PSTv-37(58.3), } \\
\text { PSTv-52(25.0) }\end{array}$ \\
\hline $\begin{array}{l}\text { Western } \\
\text { regions (R1-R6) }\end{array}$ & 311 & 34 & $\begin{array}{l}\text { PSTv-1(0.3), PSTv-2(0.3), PSTv-3(1.6), } \\
\text { PSTv-4(6.1), PSTv-5(0.6), PSTv-8(1.0), } \\
\text { PSTv-11(39.9), PSTv-13(0.6), PSTv-14(13.2), } \\
\text { PSTv-17(2.6), PSTv-18(0.6), PSTv-21(0.3), } \\
\text { PSTv-30(2.6), PSTv-31(1.3), PSTv-32(0.3), } \\
\text { PSTv-33(0.6), PSTv-34(1.9), PSTv-35(1.0), } \\
\text { PSTv-36(0.3), PSTv-37(7.4), PSTv-38(0.3), } \\
\text { PSTv-39(1.6), PSTv-40(0.6), PSTv-41(2.6), } \\
\text { PSTv-42(1.9), PSTv-43(2.9), PSTv-44(1.0), } \\
\text { PSTv-45(0.3), PSTv-46(1.9), PSTv-47(1.3), } \\
\text { PSTv-48(0.3), PSTv-49(1.6), PSTv-50(0.3), } \\
\text { PSTv-51(0.6) }\end{array}$ & 180 & 20 & $\begin{array}{l}\text { PSTv-4(5.0), PSTv-11(18.9), PSTv-14(15.6), } \\
\text { PSTv-17(0.6), PSTv-19(0.6), PSTv-28(0.6), } \\
\text { PSTv-32(0.6), PSTv-34(0.6), PSTv-35(1.1), } \\
\text { PSTv-36(1.1), PSTv-37(29.4), PSTv-40(1.1), } \\
\text { PSTv-43(1.1), PSTv-46(2.2), PSTv-47(1.1), } \\
\text { PSTv-48(8.3), PSTv-52(4.4), PSTv-53(6.7), } \\
\text { PSTv-64(0.6), PSTv-71(0.6) }\end{array}$ \\
\hline $\begin{array}{l}\text { Eastern } \\
\text { regions (R7-R12) }\end{array}$ & 38 & 8 & $\begin{array}{l}\text { PSTv-28(2.6), PSTv-30(2.6), PSTv-31(13.2), } \\
\text { PSTv-33(5.3), PSTv-34(15.8), PSTv-35(2.6), } \\
\text { PSTv-36(2.6), PSTv-37(55.3) }\end{array}$ & 161 & 11 & $\begin{array}{l}\text { PSTv-11(3.7), PSTv-14(3.7), PSTv-28(2.5), } \\
\text { PSTv-32(1.9), PSTv-31(0.6), PSTv-34(1.2), } \\
\text { PSTv-35(2.5), PSTv-37(67.7), PSTv-39(0.6), } \\
\text { PSTv-47(0.6), PSTv-52(14.9) }\end{array}$ \\
\hline
\end{tabular}

\footnotetext{
a Predominant races are in bold.

b Regions: R1 = eastern Washington, northeastern Oregon, and northern Idaho; R2 = western Montana and southern Alberta, Canada; R3 = southern Idaho, southeastern Oregon, northern Nevada, northern Utah, western Wyoming, and western Colorado; R4 = western Oregon and northern California; R5 = northwestern Washington and southwestern British Columbia, Canada; R6 = central and southern California, Arizona, and western New Mexico; R7 = Texas, Louisiana, Arkansas, Oklahoma, and eastern New Mexico; R8 = Kansas, Nebraska, and eastern Colorado; R9= South Dakota, North Dakota, Minnesota, eastern Montana, and southern Manitoba and southern Saskatchewan, Canada; R10 = Mississippi, Alabama, Florida, Georgia, South Carolina, North Carolina, Tennessee, and Kentucky; R11 = Missouri, Illinois, Indiana, Iowa, Wisconsin, Michigan, and Ontario, Canada; and R12 = Virginia, West Virginia, Ohio, Maryland, Pennsylvania, and New York. Western regions include R1 to R6 and Eastern regions include R7 to R12 (Chen 2005; Chen et al. 2010; Wan and Chen 2014).
} 
in 2011 and mostly in the western region in 2012. The PSTv-37 group was detected throughout the country. This result is consistent with the previous reports about these major race groups (Cheng and Chen 2014; Wan and Chen 2014). The shift of the most predominant

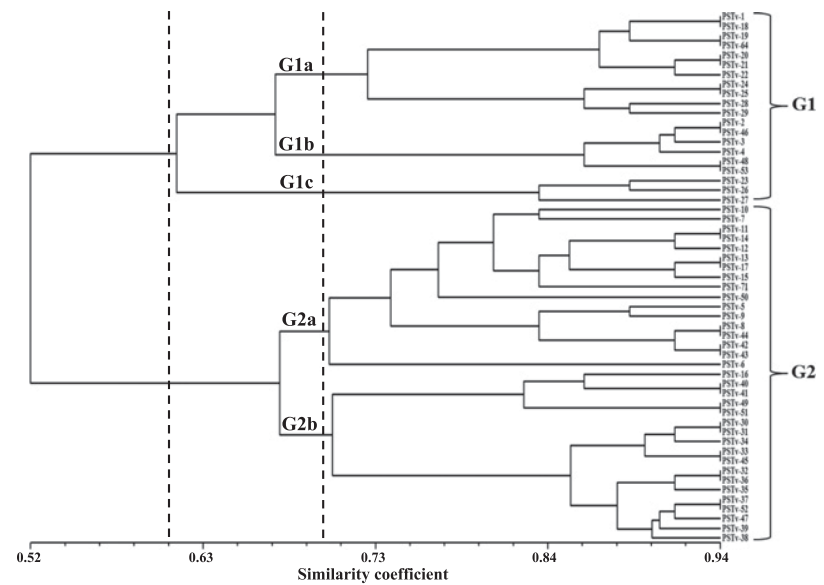

Fig. 3. Dendrogram showing the relationships among 55 Puccinia striiformis f. sp. tritici races identified based on their avirulence or virulence reactions on the $18 \mathrm{Yr}$ singlegene differentials using the unweighted pair group method with the arithmetic means in the NTSYS program.

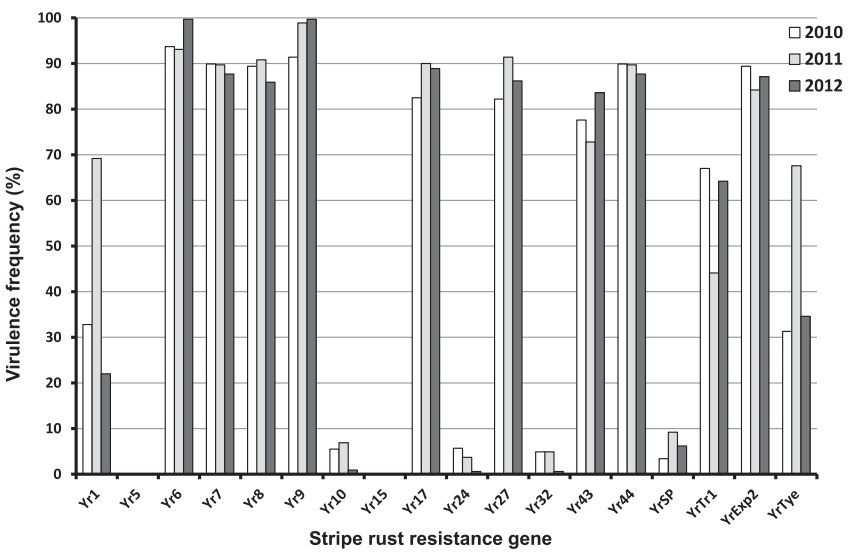

Fig. 4. Frequency changes of virulences to the $18 \mathrm{Yr}$ single-gene lines used to differentiate races of Puccinia striiformis f. sp. tritici in the United States in 2010, 2011, and 2012. race from PSTv-11 to PSTv-37 was due to the shift of stripe rust epidemic levels from the west to the east from 2011 to 2012. The PSTv11 group is equivalent to the PST-127 race group based on the old set of wheat cultivar differentials. PST-127 was identified for the first time in 2007 from two samples, one from California (R6) and the other from Washington (R1), as the most virulent race producing high IT on 17 of the 20 differentials (Chen et al. 2010). The race has evolved into several races with a reduced number of virulences in the following years, and the race group quickly became the predominant one and caused severe epidemics in 2010 and 2011 in the western United States (Wan and Chen 2012, 2014). The emergence of race group PSTV-11 (PST-127) in the western United States is probably due to its broad spectrum of virulence, including those to resistance genes found in commercial cultivars such as $\mathrm{Yrl}, \mathrm{Yr} 17$, Yr43, Yr44, YrExp2, and YrTye. Although cultivars with these resistance genes might have selected the PSTV-11 race group, the severe or extremely severe epidemics in both 2010 and 2011 were mostly enabled by weather conditions unusually favorable for stripe rust, which also reduced the effectiveness of various levels of HTAP resistance that is largely nonrace specific but influenced by temperatures and inoculum loads (Chen 2005, 2013, 2014). The severe epidemics in 2010 and 2011 in the western United States indicate the need to develop wheat cultivars with HTAP plus additional effective resistance genes.

Similarly, the severe epidemics of stripe rust in 2010 and 2012 but not in 2011 in the eastern United States were mainly caused by weather changes. The effect of race change on the epidemics was relatively limited. The predominant race, PSTv-37, was the same in all 3 years. In 2010, the occurrence of PSTV-37 ranged from 45.5 to $70.0 \%$ in the different regions of the eastern United States (Wan and Chen 2014) (http://striperust.wsu.edu). In 2011, it was the most frequent race in all six eastern regions (R7 to R12), ranging from 42.9 to $66.7 \%$. In 2012, PSTv-37 was the most common race at 58.3 to $100 \%$ among the six regions. PSTv-37 is virulent to resistance gene $\mathrm{Yr17}$, and the majority of other races detected in the eastern regions from 2010 to 2012 are also virulent to $\operatorname{Yr} 17$. Yrl7 is an important gene used in the wheat breeding programs in the eastern United States because it is linked to leaf rust resistance gene $\operatorname{Lr} 37$ and stem rust resistance gene $\mathrm{Sr} 38$, originally from Triticum ventricosum (syn. Aegilops ventricosa) (McIntosh et al. 1995). In 2010, Yr17-virulent races accounted for $83.3 \%$ in the eastern regions, ranging from $50.0 \%$ in $\mathrm{R} 10$ to $100 \%$ in $\mathrm{R} 8$. These races increased to $89.5 \%$ in 2011 , ranging from $78.6 \%$ in $\mathrm{R} 7$ to $100 \%$ in $\mathrm{R} 8$, R9, R10, and $\mathrm{R} 12$; and to $98.1 \%$ in 2012 , ranging from $91.7 \%$ in $\mathrm{R} 12$ to $100 \%$ in R7, R9, R10, and R11 (Wan and Chen 2014) (http://striperust. wsu.edu). The severe stripe rust on wheat cultivars with $\operatorname{Yr} 17$ in

Table 5. Coefficients of association between virulences (Vir) to $18 \mathrm{Yr}$ genes determined using the isolates of Puccinia striiformis f. sp. tritici collected in the United States in 2011 and 2012

\begin{tabular}{|c|c|c|c|c|c|c|c|c|c|c|c|c|c|c|c|c|c|}
\hline \multirow[b]{2}{*}{ Vir to } & \multicolumn{17}{|c|}{ Vir to } \\
\hline & YrTye & YrExp2 & YrTr1 & $\mathrm{YrSP}$ & Yr44 & Yr43 & Yr32 & Yr27 & Yr24 & Yr17 & Yr15 & Yr10 & $Y r 9$ & Yr8 & Yr7 & Yr6 & Yr5 \\
\hline$Y r 1$ & 0.97 & -0.35 & -0.62 & 0.28 & -0.29 & -0.13 & -0.06 & 0.09 & -0.06 & -0.04 & 0.00 & -0.10 & 0.06 & -0.24 & -0.29 & -0.16 & 0.00 \\
\hline $\operatorname{Yr} 5$ & 0.00 & 0.00 & 0.00 & 0.00 & 0.00 & 0.00 & 0.00 & 0.00 & 0.00 & 0.00 & 1.00 & 0.00 & 0.00 & 0.00 & 0.00 & 0.00 & $\ldots$ \\
\hline Yr6 & -0.15 & 0.35 & 0.21 & 0.06 & 0.00 & 0.37 & 0.03 & 0.00 & 0.03 & 0.35 & 0.00 & 0.04 & 0.25 & 0.00 & 0.00 & $\ldots$ & $\ldots$ \\
\hline$Y r 7$ & -0.29 & 0.87 & 0.39 & -0.58 & 1.00 & 0.67 & 0.06 & 0.39 & 0.06 & 0.36 & 0.00 & 0.07 & 0.24 & 0.91 & $\ldots$ & $\ldots$ & $\ldots$ \\
\hline$Y r 8$ & -0.24 & 0.79 & 0.39 & -0.57 & 0.91 & 0.67 & 0.06 & 0.47 & 0.06 & 0.37 & 0.00 & 0.07 & 0.24 & $\ldots$ & $\ldots$ & $\ldots$ & $\ldots$ \\
\hline $\operatorname{Yr} 9$ & 0.09 & 0.21 & 0.09 & 0.03 & 0.24 & 0.16 & 0.01 & 0.24 & 0.02 & 0.19 & 0.00 & 0.02 & $\ldots$ & $\ldots$ & $\ldots$ & $\ldots$ & $\ldots$ \\
\hline Yr10 & -0.09 & 0.08 & 0.19 & 0.02 & 0.07 & 0.09 & 0.83 & 0.05 & 0.81 & -0.05 & 0.00 & $\ldots$ & $\ldots$ & $\ldots$ & $\ldots$ & $\ldots$ & $\ldots$ \\
\hline $\operatorname{Yr} 15$ & 0.00 & 0.00 & 0.00 & 0.00 & 0.00 & 0.00 & 0.00 & 0.00 & 0.00 & 0.00 & $\ldots$ & $\ldots$ & $\ldots$ & $\ldots$ & $\ldots$ & $\ldots$ & $\ldots$ \\
\hline Yr17 & -0.04 & 0.44 & 0.13 & -0.11 & 0.36 & 0.54 & -0.06 & 0.58 & -0.05 & $\ldots$ & $\ldots$ & $\ldots$ & $\ldots$ & $\ldots$ & $\ldots$ & $\ldots$ & $\ldots$ \\
\hline Yr24 & -0.06 & 0.07 & 0.16 & 0.01 & 0.06 & 0.09 & 0.97 & 0.06 & $\ldots$ & $\ldots$ & $\ldots$ & $\ldots$ & $\ldots$ & $\ldots$ & $\ldots$ & $\ldots$ & $\ldots$ \\
\hline$Y r 27$ & 0.09 & 0.32 & 0.06 & -0.12 & 0.39 & 0.52 & 0.06 & $\ldots$ & $\ldots$ & $\ldots$ & $\ldots$ & $\ldots$ & $\ldots$ & $\ldots$ & $\ldots$ & $\ldots$ & $\ldots$ \\
\hline Yr32 & -0.05 & 0.07 & 0.16 & 0.02 & 0.06 & 0.09 & $\ldots$ & $\ldots$ & $\ldots$ & $\ldots$ & $\ldots$ & $\ldots$ & $\ldots$ & $\ldots$ & $\ldots$ & $\ldots$ & $\ldots$ \\
\hline Yr43 & -0.12 & 0.75 & 0.28 & -0.37 & 0.67 & $\ldots$ & $\ldots$ & $\ldots$ & $\ldots$ & $\ldots$ & $\ldots$ & $\ldots$ & $\ldots$ & $\ldots$ & $\ldots$ & $\ldots$ & $\ldots$ \\
\hline Yr44 & -0.29 & 0.87 & 0.39 & -0.58 & $\ldots$ & $\ldots$ & $\ldots$ & $\ldots$ & $\ldots$ & $\ldots$ & $\ldots$ & $\ldots$ & $\ldots$ & $\ldots$ & $\ldots$ & $\ldots$ & $\ldots$ \\
\hline$Y r S P$ & 0.28 & -0.53 & -0.28 & $\ldots$ & $\ldots$ & $\ldots$ & $\ldots$ & $\ldots$ & $\ldots$ & $\ldots$ & $\ldots$ & $\ldots$ & $\ldots$ & $\ldots$ & $\ldots$ & $\ldots$ & $\ldots$ \\
\hline YrTrl & -0.63 & 0.44 & $\ldots$ & $\ldots$ & $\ldots$ & $\ldots$ & $\ldots$ & $\ldots$ & $\ldots$ & $\ldots$ & $\ldots$ & $\ldots$ & $\ldots$ & $\ldots$ & $\ldots$ & $\ldots$ & $\ldots$ \\
\hline$Y r E x p 2$ & -0.33 & $\ldots$ & $\ldots$ & $\ldots$ & $\ldots$ & $\ldots$ & $\ldots$ & $\ldots$ & $\ldots$ & $\ldots$ & $\ldots$ & $\ldots$ & $\ldots$ & $\ldots$ & $\ldots$ & $\ldots$ & $\ldots$ \\
\hline
\end{tabular}


the eastern regions in 2010 and 2012 was due mainly to weather conditions rather than to race changes. Stripe rust was not easily found on cultivars with $\operatorname{Yr} 17$ in 2011, when conditions were not favorable to the disease in the eastern regions. Based on our field observations and greenhouse tests (A. M. Wan and X. M. Chen, unpublished data), Yr17 is hypothesized to be linked to an HTAP resistance gene on the translocated $T$. ventricosum chromosome. We are conducting a study to test the hypothesis. Nevertheless, $\operatorname{Yr} 17$ is still useful because wheat cultivars with this gene have HTAP resistance, although most $P$. striiformis f. sp. tritici races identified in recent years are virulent to $\mathrm{Yr} 17$. However, the gene should be combined with other effective resistance genes because the HTAP resistance conferred by a $\mathrm{Yr} 17$ linked gene may not provide adequate control when temperatures are low. Similarly, in the western regions, the various levels of HTAP resistance in all commercial wheat cultivars also should be increased to an adequate level for protecting crops under severe stripe rust epidemics such as those in 2010 and 2011.

Fourteen races (PSTv-42 to PSTv-53, PSTv-64, and PSTv-71) were identified in 2011 and 2012 but were not identified in 2010, when the new set of $Y r$ single-gene line differentials was first used (Wan and Chen 2014). These races are considered "new" in the present study. However, some of the races might have existed before 2010. Testing of historical isolates with the new set of differentials is underway, which should help determine the evolutionary relationships for races of $P$. striiformis f. sp. tritici. From the testing of isolates of the new races on the old set of wheat cultivar differentials, we found that the 14 new races were equivalent to 10 PST races (Chen et al. 2010; Wan and Chen 2012) and 5 of the PST races were not identified before 2011. Among the 14 new PSTv races, the most notable race is PSTv-51 because it is virulent to all $Y r$ genes in the 18 single-gene lines, except for $\operatorname{Yr} 5$ and $\operatorname{Yr} 15$. Because we identified this race, we have included it in the set of selected races for screening wheat germplasm and breeding lines for resistance to stripe rust. Compared with other selected races, more susceptible accessions have been identified with PSTv-51 than other races (X. M. Chen, Y. M. Liu, and C. K. Evans, unpublished data). Fortunately, this race has not been detected after 2011 (A. M. Wan and X. M. Chen, unpublished data) (http://striperust.wsu.edu).

The cluster analysis showed the virulence relationships of the 55 races identified in 2010 to 2012. Most of the new races identified in 2011 and 2012 appear to have evolved from previously existing races through a single virulence mutation. For examples, PSTv-42, PSTv-43, and PSTv-44 are closely related to PSTv-8; PSTv-45 is related to PSTv-33; PSTv-46 to PSTv-2; and PSTv-64 to PSTv-19. None of the new races appear to be introduced from outside the United States based on the virulence data. To strengthen this conclusion, the genetic relationships of the races should be studied using molecular markers.

We also tested isolates of PSTv races on seven wheat varieties as supplementary differentials. The results showed that $Y r 2, Y r 25, Y r 28$, $Y r 31, Y r A$, and $Y r 3$ and $Y r V 23$ in Vilmorin 23 are largely ineffective because all or most PSTv races identified from 2010 to 2012 are virulent on wheat lines with these genes. In contrast, most races are avirulent on Hybrid 46 ( $Y r 4$ and $Y r H 46)$ and, therefore, its resistance still has some value in breeding for stripe rust resistance.

From 2010 to 2012, virulences to $\operatorname{Yr} 6, \operatorname{Yr} 7, \operatorname{Yr} 8, \operatorname{Yr} 9, \operatorname{Yr} 17, \operatorname{Yr} 27$, $Y r 43, Y r 44$, and $Y r E x p 2$ were very high (>70\%), indicating that these resistance genes are not useful in breeding programs. In contrast, virulences to $\mathrm{Yr} 10, \mathrm{Yr} 24, \mathrm{Yr} 32$, and $\mathrm{YrSP}$ were very low, suggesting that these resistance genes have some value in breeding programs. Similar to previous studies (Chen et al. 2010; Sharma-Poudyal et al. 2013; Wan and Chen 2012, 2014), virulences to $\operatorname{Yr} 5$ and $\operatorname{Yr} 15$ were not detected, making them more valuable than other resistance genes in the differentials for use in breeding programs. When combinations of resistance genes are considered for use in breeding programs, those with highly associated virulences should be avoided and those with low positive- or negative-associated (disassociated) virulences may be used with caution. However, it is better to combine resistance genes without identified virulences, such as $\mathrm{Yr} 5$ and $\mathrm{Yr} 15$ in the differentials, and many others not used as differentials, such as $\mathrm{Yr} 45$,
Yr53, Yr64, and Yr65 (Cheng et al. 2014; Li et al. 2010; Xu et al. 2013). Caution is still needed because these genes confer all-stage resistance and may not be durable. The best strategy is to combine these effective all-stage resistance genes with HTAP resistance genes, such as Yr52, Yr59, Yr62, and many others (Chen 2013; Lu et al. 2014; Ren et al. 2012; Zhou et al. 2014). Cultivars with such combinations of all-stage resistance and HTAP resistance may overcome the disadvantages of both types of resistance and provide high-level and durable resistance to stripe rust (Chen 2005, 2013, 2014).

The PSTv series has been used for naming $P$. striiformis f. sp. tritici races because it is simple, reflecting the relative sequential order of races identified, and facilitates communication (Wan and Chen 2014). In addition, we have adapted the octal system proposed by several scientists for naming pathogen races (Gilmour 1973; Habgood 1970; Herrmann et al. 1999; Johnson 1999). However, some of the codes we used in the previous study (Wan and Chen 2014) were different from those used by others (Gilmour 1973; Habgood 1970; Herrmann et al. 1999; Johnson 1999). We have made modifications in the present study. The modified codes, the same as used by others, correspond more nicely to the binary codes (Table 1). The advantage of the octal codes is that they shorten race names compared with the binary system. Although the octal code can be used to determine the relationships among races to some degree, the binary system can provide more detailed information on relationships between the races. The modified codes for the $P$. striiformis $\mathrm{f}$. sp. tritici races can be easily expanded to binary codes for certain analyses. In the present study and a previous study (Wan and Chen 2014), we have taken advantage of using the octal codes to sort out races and quickly identify new races. In the present study, we used the binary data in cluster analysis to determine relationships among the races. When historical isolates are recharacterized with the new set of $Y r$ single-gene differential lines, additional races will be identified. When these are coded with the octal system, we will be able to use both the octal and binary codes to analyze the data to determine virulence relationships of different races.

\section{Acknowledgments}

This study was supported by the United States Department of AgricultureAgricultural Research Service (project number 5348-22000-015-00D), Washington Wheat Commission, and Idaho Wheat Commission. We thank the following collaborators for collecting and sending stripe rust samples in 2011 and 2012: Z. Abate, M. Acevedo, C. Aitken, T. Allen, J. Baker, J. Barnhill, A. Barta, G. Bergstrom, D. Bland, B. Blessing, M. Bonman, R. Bowden, C. Bradley, M. Burrows, K. Campbell, M. Carson, J. Chatelain, J. Chen, G. Cisar, B. Conrady, T. Gordon, G. Davies, E. De Wolf, J. Dubcovsky, R. Ellis, M. Eruin, A. Esser, B. Fanning, A. Fox, A. Greea, C. Griffey, A. Harber, S. Harrison, P. Hayes, R. Herrington, D. Hershman, B. Hunger, C. Jackson, L. Jackson, Y. Jin, D. Johnson, J. Kautz, M. Kolding, J. Kolmer, D. Long, I. Lowe, J. Marshall, S. Martinez E. Miller, M. Miller, E. Milus, L. Morscheck, T. Murray, M. Newcomb, C. Nischwitz M. Pace, B. Padgett, M. Pumphery, S. Reinertsen, L. Roach, J. Rouse, M. Rouse, M. Rugg, L. Skoglund, B. Simoneaux, J. Sthapit, B. Stougaard, A. Tenuta, S. Thompson, R. Webb, S. Wegulo, H. Wetzel, K. Wise, D. Wysock, J. Youmans, and B. Zemetra.

\section{Literature Cited}

Chen, X. M. 2005. Epidemiology and control of stripe rust [Puccinia striiformis f. sp. tritici] on wheat. Can. J. Plant Pathol. 27:314-337.

Chen, X. M. 2007. Challenges and solutions for stripe rust control in the United States. Aust. J. Agric. Res. 58:648-655.

Chen, X. M. 2011. Stripe rust, why the disease hit so hard in 2010, 2011. Wheat Life AUG/SEP:56-59.

Chen, X. M. 2013. High-temperature adult-plant resistance, key for sustainable control of stripe rust. Am. J. Plant Sci. 4:608-627.

Chen, X. M. 2014. Integration of cultivar resistance and fungicide application for control of wheat stripe rust. Can. J. Plant Pathol. 36:311-326.

Chen, X. M., Line, R. F., and Leung, H. 1993. Relationship between virulence variation and DNA polymorphism in Puccinia striiformis. Phytopathology 83:1489-1497.

Chen, X. M., Moore, M., Milus, E. A., Long, D. L., Line, R. F., Marshall, D., and Jackson, L. 2002. Wheat stripe rust epidemics and races of Puccinia striiformis f. sp. tritici in the United States in 2000. Plant Dis. 86:39-46.

Chen, X. M., Penman, L., Wan, A. M., and Cheng, P. 2010. Virulence races of Puccinia striiformis f. sp. tritici in 2006 and 2007 and development of wheat stripe rust and distributions, dynamics, and evolutionary relationships of races from 2000 to 2007 in the United States. Can. J. Plant Pathol. 32: 315-333. 
Cheng, P., and Chen, X. M. 2014. Virulence and molecular analyses support asexual reproduction of Puccinia striiformis f. sp. tritici in the U.S. Pacific Northwest. Phytopathology 104:1208-1220.

Cheng, P., Xu, L. S., Wang, M. N., See, D. R., and Chen, X. M. 2014. Molecular mapping of genes Yr64 and Yr65 for stripe rust resistance in hexaploid derivatives of durum wheat accessions PI 331260 and PI 480016. Theor. Appl. Genet. 127:2267-2277.

Gilmour, J. 1973. Octal notation for designating physiologic races of plant pathogens. Nature 242:620.

Habgood, R. M. 1970. Designation of physiological races of plant pathogens. Nature 227:1268-1269.

Herrmann, A., Löwer, C. F., and Schachtel, G. A. 1999. A new tool for entry and analysis of virulence data for plant pathogens. Plant Pathol. 48:154-158.

Johnson, R. 1999. The use of binary and octal notation for designating races of plant pathogens. Plant Pathol. 48:159-160.

Li, Q., Chen, X. M., Wang, M. N., and Jing, J. X. 2010. Yr45, a new wheat gene for stripe rust resistance mapped on the long arm of chromosome 3D. Theor. Appl. Genet. 122:189-197.

Line, R. F. 2002. Stripe rust of wheat and barley in North America: A retrospective historical review. Annu. Rev. Phytopathol. 40:75-118.

Line, R. F., and Qayoum, A. 1992. Virulence, aggressiveness, evolution, and distribution of races of Puccinia striiformis (the cause of stripe rust of wheat) in North America, 1968-87. USDA-ARS Tech. Bull. 1788.

Lu, Y., Wang, M. N., Chen, X. M., See, D., Chao, S. M., and Jing, J. X. 2014. Mapping of Yr62 and a small effect QTL for high-temperature adult-plant resistance to stripe rust in spring wheat PI 192252. Theor. Appl. Genet. 127: 1449-1459.

McIntosh, R. A., Wellings, C. R., and Park, R. F. 1995. Wheat Rusts, an Atlas of Resistance Genes. Kluwer Academic Publishers, Dordrecht, The Netherlands.

Ren, R. S., Wang, M. N., Chen, X. M., and Zhang, Z. J. 2012. Characterization and molecular mapping of $\operatorname{Yr} 52$ for high-temperature adult-plant resistance to stripe rust in spring wheat germplasm PI 183527. Theor. Appl. Genet. 125: 847-857.
Rohlf, F. J. 2008. NTSYSpc: Numerical Taxonomy System, ver. 2.20. Exeter Publishing, Ltd., Setauket, NY.

Sharma-Poudyal, D., Chen, X. M., and Rupp, R. 2014. Potential oversummering and overwintering regions for the wheat stripe rust pathogen in the contiguous United States. Int. J. Biometeorol. 58:987-997.

Sharma-Poudyal, D., Chen, X. M., Wan, A. M., Zhan, G. M., Kang, Z. S., Cao, S. Q., Jin, S. L., Morgounov, A., Akin, B., Mert, Z., Shah, S. J. A., Bux, H., Ashraf, M., Sharma, R. C., Madariaga, R., Puri, K. D., Wellings, C., Xi, K. Q., Manninger, K., Wanyera, R., Ganzalez, M. I., Koyda, M., Sanin, S., and Patzek, L. J. 2013. Virulence characterization of international collections of the wheat stripe rust pathogen, Puccinia striiformis f. sp. tritici. Plant Dis. 97:379-386.

Sokal, R. R., and Rohlf, F. J. 1995. Biometry. W. H. Freeman, New York.

Wan, A. M., and Chen, X. M. 2012. Virulence, frequency, and distribution of races of Puccinia striiformis f. sp. tritici and P. striiformis f. sp. hordei identified in the United States in 2008 and 2009. Plant Dis. 96:67-74.

Wan, A. M., and Chen, X. M. 2014. Virulence characterization of Puccinia striiformis $\mathrm{f}$. sp. tritici using a new set of $Y r$ single-gene line differentials in the United States in 2010. Plant Dis. 98:1534-1542.

Wellings, C. R. 2011. Global status of stripe rust: A review of historical and current threats. Euphytica 179:129-141

Wellings, C. R., Singh, R. P., McIntosh, R. A., and Pretorius, Z. A. 2004. The development and application of near isogenic lines for the stripe (yellow) rust pathosystem. In: Proc. 11th Int. Cereal Rusts Powdery Mildew Conf. Norwich, England. Online publication. Abstr. A1.39 Cereal Rusts Powdery Mildews Bull. www.crpmb.org/icrpmc11/abstracts.htm

Xu, L. S., Wang, M. N., Cheng, P., Kang, Z. S., Hulbert, S. H., and Chen, X. M 2013. Molecular mapping of $\operatorname{Yr53}$, a new gene for stripe rust resistance in durum wheat accession PI 480148 and its transfer to common wheat. Theor. Appl. Genet. 126:523-533.

Zhou, X. L., Wang, M. N., Chen, X. M., Lu, Y., Kang, Z. S., and Jing, J. X. 2014 Identification of Yr59 conferring high-temperature adult-plant resistance to stripe rust in wheat germplasm PI 178759. Theor. Appl. Genet. 127:935-945. 